\title{
RAEB II type of myelodysplastic syndrome associated with axillary abscesses - Case Report
}

\author{
Bożena Sokołowska ${ }^{1, A-D \oplus}$, Daria Majowicz ${ }^{1, C-D \oplus}$, Magdalena Kozioł ${ }^{1, C-D \oplus}$, Olga Czabak ${ }^{1, C-D \oplus}$, \\ Ewa Wąsik-Szczepanek ${ }^{1, E \oplus}$, Adrian Juda ${ }^{1, C \oplus}$, Maria Soroka-Wojtaszko ${ }^{1, C \oplus}$, Marek Hus ${ }^{1, E-F \oplus}$ \\ ${ }^{1}$ Department of Haematooncology and Bone Marrow Transplantation, Medical University, Lublin, Poland \\ A - Research concept and design, B - Collection and/or assembly of data, C - Data analysis and interpretation, \\ $D$ - Writing the article, E - Critical revision of the article, F- Final approval of the article
}

\begin{abstract}
Sokołowska B, Majowicz D, Kozioł M, Czabak O, Wąsik-Szczepanek E, Juda A, Soroka-Wojtaszko M, Hus M. RAEB II type of myelodysplastic syndrome associated with axillary abscesses - Case Report. Ann Agric Environ Med. 2021; 28(4): 733-736. doi: 10.26444/aaem/140006
\end{abstract}

\begin{abstract}
Myelodysplastic syndromes (MDS) are clonal haematopoetic stem cells disorders, characterized by bone marrow dysplasia, ineffecitive haematopoesis and cytopenias. Due to neutropenia, infections are common. A case is presented of a patient with high-risk myelodysplastic syndrome (MDS) complicated by hidradenitis suppurativa that developed in both axillae. Abscesses required multiple incisions and drainage. After five cycles of treatment with azacitidine, the patient underwent allogenic bone marrow transplantation. Unfortunately, six months after the procedure, the patient lost post-transplant chimerism.Treatment with azacitidine was re-started. After the subsequent ten months, blast transformation was observed. Skin lesions in the course of hidradenitis suppurative persisted and were still considerably active.
\end{abstract}

\section{Key words}

infections, azacytidine, myelodysplatic syndromes

\section{INTRODUCTION}

Myelodysplastic syndromes (MDS) constitute a heterogeneous group of clonal stem cell disorders, characterized by the presence of cytopenias in the blood, dysplasias in bone marrow, and a propensity to progress to acute myeloid leukemia (AML) [1]. Susceptibility to serious infections, especially bacterial infections, can also occur [2]. Infections remain the main cause of death in low-risk MDS patients [2]. The aim of this case report is to present a patient with high-risk myelodysplastic syndrome (MDS) complicated by hidradenitis suppurativa that developed in both axillae.

\section{CASE REPORT}

In August 2014, a 52 year-old female patient was admitted to the Department of Haematology and Bone Marrow Transplantation, complaining of exercise intolerance and recurrence of axillary abscesses, which required a surgical drainage procedure. Thrombocytopenia (PLT-35K/uL) and anaemia $(\mathrm{Hgb}-7.6 \mathrm{~g} / \mathrm{dl})$ were present. White blood cell count was elevated (WBC - 10.97G/1), neutrophil count was within the normal range $(5,4 \mathrm{G} / \mathrm{l})$. Both red cells and platelet transfusion were needed from the onset of the treatment. Trephine biopsy with bone marrow aspiration was performed. Bone marrow smear revealed increased cellularity with a domination of red cells from early to late stages of development, with secondary dysplastic feature with blasts comprising $12 \%$ of bone marrow cellularity. Immunophenotyping by flow cytometry analysis showed: 2 populations of blasts: $6 \%$ of myeloblasts of CD117+,

Address for correspondence: Adrian Juda, Department of Haematooncology and Bone Marrow Transplantation, Medical University, Aleje Racławickie 1, 20-059 Lublin, Poland

E-mail: adrianjuda@op.pl

Received: 14.04.2021; accepted: 07.06.2021; first published: 20.09.2021
CD33+, CD34-, CD15-, MPO+ phenotype, and about 17\% of monocytoidal cells with phenotype: CD117+, CD33 high, CD34-, CD11 c+, CD56-, CD13-, CD14-, CD64+, CD65+ $\mathrm{DR}+$ and MPO-.

Cytogenetics revealed normal karyotype 46,XX. Molecular studies showed mutation in an NPM1 gene. The patient was diagnosed with myelodysplastic syndrome RAEB II of a very high risk according to IPSS-R [3]. Due to the patient's age, being in a very high risk group and with comorbidities (axillary abscesses) she was started on Azacitidine in a dose of $75 \mathrm{mg} / \mathrm{m} 2$ for 7 days per month.

From August 2014 - February 2015, the patient received 5 cycles of Azacitidine. Bone marrow biopsy was repeated during the $3^{\text {rd }}$ cycle which revealed a decrease in blasts (1\%) and monocytoidal cells (4\%). As there was a response to the treatment, Azacitidine was continued. She was considered for allogenic stem cell transplantation (alloSCT) from a matched sibling donor (10/10).

Heavy menstrual bleedings had already been observed prior to the first hospitalisation in the Haematology Department. In the course of gynaecological examination, uterine fibroids were found, which required treatment by Lynestrenol. Following hospitalizations were complicated by recurrent hidradenitis suppurativa in both axillae. Abscesses were incised and drained multiple times by surgery. Empiric antibiotics (amoxicillin+ clavulanic acid and clindamycin) was given due to the high risk of infectious complications.

Initially, only physiological flora of the skin was present in cultures. Proteus mirabilis growth was obtained after one incision of the axillary abscesses. Targeted antibiotic therapy was used according to the antibiogram. Details of bacteriological tests and treatment utilized is depicted in Table 1.

The last hospitalisation before alloSCT was also complicated by another abscess that developed in the right axilla. Physiological flora of the skin was present in the wound culture. Amoxicillin + clavulanic acid and 
Table 1. Bacteriological results and treatment of axillary abscesses

\begin{tabular}{|c|c|c|}
\hline DATE & $\begin{array}{l}\text { RESULT OF SKIN/ WOUND } \\
\text { CULTURE }\end{array}$ & TREATMENT \\
\hline 12.09 .2014 & physiological flora of the skin & none \\
\hline 10.10 .2014 & physiological flora of the skin & none \\
\hline 21.11 .2014 & $\begin{array}{l}\text { Proteus mirabillis }+++ \\
\text { (left axilla) }\end{array}$ & $\begin{array}{l}\text { Clindamycin- } \\
\text { antibiotic for empiric therapy. } \\
\text { Ceftazidime }+ \\
\text { Amikacin- targeted antibiotic. } \\
\text { Ciprofloxacin- prevention. }\end{array}$ \\
\hline 09.02 .2015 & physiological flora of the skin & none \\
\hline 19.03 .2015 & physiological flora of the skin & none \\
\hline 29.04 .2015 & physiological flora of the skin & none \\
\hline 27.04 .2016 & $\begin{array}{l}\text { Pseudomonas aeruginosa MBL(-) } \\
\text { (left axilla) }\end{array}$ & $\begin{array}{l}\text { Trimethoprim- } \\
\text { Sulfamethoxazole }\end{array}$ \\
\hline 18.07.2016 & $\begin{array}{l}\text { Pseudomonas aeruginosa MBL(-) } \\
\text { (left axilla) }\end{array}$ & $\begin{array}{l}\text { Hospitalization - Department } \\
\text { of General Surgery }\end{array}$ \\
\hline 18.08 .2016 & $\begin{array}{l}\text { Klebsiella pneumoniae ESBL (+) } \\
\text { (right axilla) }\end{array}$ & $\begin{array}{l}\text { Cefepim, Ciprofloxacin. } \\
\text { Change: Ceftazidime + } \\
\text { Amikacin. } \\
\text { Change: Meropenem + } \\
\text { Amikacin. }\end{array}$ \\
\hline 13.09 .2016 & $\begin{array}{l}\text { Pseudomonas aeruginosa MBL(-) } \\
\text { (left axilla) }\end{array}$ & $\begin{array}{l}\text { Continuation: Meropenem + } \\
\text { Amikacin. }\end{array}$ \\
\hline
\end{tabular}

fluconazole were used along with incision and drainage of the abscess. Alanine transaminase (ALT) and aspartate transaminase (AST) became elevated. As that was probably the result of Lynestrenol use, the drug was discontinued and hepatoprotective treatment was started. The sixth cycle of azacitidine treatment was discontinued. At the same time, the stem cells of the patient's brother were mobilised and collected.

In April 2015, the patient received $4 \times 10^{\wedge} 6 \mathrm{CD} 34+$ cells per $\mathrm{kg}$ of body weight. Conditioning regimen was Cy2BU. Posttransplant period was complicated by late onset of nausea, vomiting and mucositis CTCAE grade 1. GVHD prophylaxis comprised cyclosporine and MTX. Features of bone marrow regeneration: ANC $>0.5 \mathrm{G} / \mathrm{L}, \mathrm{PLT}>50 \mathrm{G} / \mathrm{L}$ were obtained on +29 days after alloSCT.

Due to a rapid loss of post-transplant chimerism (6 months), donor lymphocyte infusion was performed twice: +203 day after HSCT $1 \times 10^{\wedge} 7 / \mathrm{kg} \mathrm{CD} 3+$ cells and +217 day after HSCT $50 \times 10^{\wedge} 6 / \mathrm{kg}$ CD $3+$ cells. Numerous transfusions of red blood cells and platelet concentrates were necessary.

In December 2015, MRD assessment in the bone marrow was performed. Immunophenotyping by flow cytometry showed 2 populations of cells: $6.31 \%$ myeloblasts with CD117+, CD33+, CD34+ phenotype and $6.43 \%$ monocytoidal cells with: CD117-, CD33 high, CD34-, CD11c+, CD13-, CD64+, CD56-. On the basis of the afore-mentioned results, recurrence of the underlying disease was diagnosed.

Due to the complete loss of posttransplant chimerism, the patient was disqualified from another alloSCT, and treatment with Azacitidine was re-started. She received 4 cycles of Azacitidine until April 2016. During that time, the recurrent abscesses in both axillae required several surgical incisions and drainages. In June 2016, the patient was hospitalised in the Surgery Department to have the necrotic lymph nodes and part of the skin with fistula removed.

In September 2016, the patient was again admitted to the Department of Haematology due to severe trombocythopenia
(PLT 7K/uL, Hb 7,5g/dl, WBC 66,32K/uL) and suspicion of AML transformation.

The findings of the bone marrow immunophenotypic examination included: blasts with phenotype: $\mathrm{CD} 33+, \mathrm{CD} 34$ $+, \mathrm{CD} 117+, \mathrm{DR}+, \mathrm{CD} 15+-(54 \%), \mathrm{CD} 11 \mathrm{c}+(66 \%), \mathrm{MPO}-$ + (29\%), CD65 - + (29\%), CD56-, CD64-, CD13 - + (17\%) which accounted for approximately $86 \%$ of bone marrow cells. Due to persisting axillary abscesses with purulent discharge, intensive chemotherapy was discontinued. Hydroxycarbamide cytoreductive therapy was initiated. In September 2016, the patient's general condition worsened haemoptysis, increased dyspnea, and signs of discreet paresis of the right lower limb. The CT of the head did not show any bleeding. On the same day, the patient died in the mechanism of cardiac and respiratory arrest, preceded by a sudden loss of consciousness. Table 2 summarizes the patient's course of treatment.

Table 2. Treatment schedule

- first cycle-25.08 - 19.09.2014/ second cycle-06.10 - 17.10.2014/ third cycle$12.11-27.11 .2014$ / fourth cycle-29.12.2014 $-07.01 .2015 /$ fifth cycle-04.02 16.02 .2015

- Allogeneicstem cell transplantation from a related donof $\mathbf{1 0 . 0 4 . 2 0 1 5}$

- +203 days $-1 \times 10^{\wedge} 7$ cells $\mathrm{CD} 3+/+217$ days $-50 \times 10^{\wedge} 6$ cells $\mathrm{CD} 3+$

- first cycle- 01.01 - 12.01.2016 / second cycle- 04.02 - 10.02.2016 / third cycle $8.03-14.03 .2016 /$ fourth cycle- $14.04-20.04 .2016$

- 13.09.2016

\section{DISCUSSION}

To the best of the authors' knowledge, this is the first case report of the coexistence of hidradenitis suppurativa, a skin bacterial disease and myelodysplastic syndrome. High risk of serious infections in patients diagnosed with myelodysplastic syndromes is based both on haaematological disorder and patient's characteristics. The factors increasing the risk of infections include older age, multiple comorbidities, and treatment with hypomethylating agents and lenalidomide. The factors associated with MDS are neutropenia and impaired neutrophils function, defects in lymphocytes B, T, NK-cells and iron overload [5]. Neutropenia occurs in up to $50 \%$ of newly-diagnosed cases. In the majority of patients (about $70-80 \%$ ), neutropenia is caused by bone marrow failure, impaired differentiation and escalated apoptosis of haematopoesis progenitors on all grades of differentiation [6].

Despite, the normal level of neutrophils $(5.4 \mathrm{G} / \mathrm{l})$ at the moment of diagnosis, the patient suffered from recurrent episodes of hidradenitis suppurativa in both axillae. Surgical intervention and antibiotics therapy were necessary. Hidradenitis suppurativa is a purulent skin disease which occurs only in adults. The origin of the apocrine glands infection is bacterial, most frequently caused by Staphylococcus aureus and often by Gram-negative bacteria (e.g. Proteus, Escherichia) [7,8,9]. In the presented case, initially only physiological flora of the skin was observed in the cultures. The cultures obtained from the abscesses revealed the presence of Proteus mirabilis, Klebsiella pneumoniae 
and Pseudomonas aeruginosa. Hormonal imbalance and obesity were the driving force for the evolution of infection. The presented patient's weight was normal, but menorrhagia was observed. Gynaecologic examination revealed myomas, and hormonal treatment with lynestrenol was started. The hormonal intervention may be associated with recurrent axial abscesses as an additional trigger factor.

Among the reasons increasing the risk of serious infections in patients with MDS and concerning the patient in the presented case, only hypomethylation treatment with azacitidine can be mentioned. The patient was neither elderly nor did she have numerous comorbidities. It has been proved that hypomethylating drugs, including azacitidine, not only contribute to the improvement of haematological parameters, but also extend the survival time of patients with MDS [10, 11]. Multifactorial analysis showed that the occurrence of infection in high-risk MDS and acute myeloid leukemia patients during azacitidine treatment was associated with transfusion dependency before the first cycle, and severe thrombocytopenia $(<20 \times 109 / 1)$ [12]. Trubiano et al. [13] analyzed the occurrence of infections in patients with MDS and acute myeloid leukemia receiving azacitidine. They demonstrated that in more than $25 \%$ of patients the first and second course of azacitidine treatment was complicated by infections, mainly bacterial, and only after the fifth cycle this percentage dropped to $<10 \%$.) Approximately $5.3 \%$ of azacitidine treatment cycles were complicated by neutropenic fever, $2 \%$ of the cycles by bacteraemia and $0.3 \%$ of the cycles - invasive aspergillosis. These authors also reported that infections were the cause of death of $23 \%$ of patients. In the presented case, it seems certain that azacitidine treatment did not contribute to the occurrence of multiple axillary abscesses as they preceded the onset of the treatment. It can be supposed that the underlying disease and azacitidine treatment made these complications difficult to control.

Azacitidine treatment resulted in a reduction in the number of blast cells, leading to the bone marrow allogenic transplantation procedure from a compatible brother. Unfortunately, chimerism after transplantation persisted only up to about 6 months after the procedure. Lymphocytes from the donor were transfused twice. It did not protect the patient from relapse, which occurred 8 months after the procedure. Azacitidine was used again in the course of the treatment. According to the Polish Leukemia Group, the use of azacitidine after bone marrow transplantation seems to extend the time of relapse effectively only when it is used as a pre-emptive or supportive treatment [14]. In 2016, the usage of azacitidine after bone marrow transplantation was not a routine procedure. Possibly progression-free survival might have been extended, allowing for more efficient treatment of the skin disease.

In the treatment of relapse after allotransplantation, azacitidine was not effective, similar to the presented case. The disease returned rapidly ( 8 months after alloSCT) and progressed to acute myeloid leukaemia (16 months after AlloSCT). The presence of skin leasions prevented an intensive treatment schedule. As a median survival in highrisk MDS treated with azacitidine as a single agent remains poor (24.4 months), there are clinical trials in which other drugs (such as venetoclax) are added to azacidine in order to improve response or survival [15]

The presented patient had a mutation in the NPM1 nucleophosmin gene. This mutation occurs in about $30 \%$ of patients with acute myeloid leukaemia with normal karyotype, and is associated with a favourable prognosis [16], but in myelodysplastic syndrome this is rare (in about $4.4 \%$ of patients), and is usually associated with a diploid karyotype [17]. The patient presented had a normal karyotype of 46XX. In this case, the coexistence of mutation in the nucleophosmin gene did not improve prognosis.

Iron overload, often observed in patients with MDS, is primarily a consequence of frequent transfusions of red blood cells, but may also result from increased absorption of iron ions due to ineffective erythropoiesis. Excess free iron ions damage the natural resistance to infection by inhibiting INF-gamma, TNF- alpha, nitric oxide production, damage the macrophages, neutrophils and T-lymphocyte function [18]. Wong et al. performed a retrospective analysis of the effect of iron overload on the occurrence of infection in patients with low-risk MDS. They showed that iron chelating treatment prolongs the time to first infection [19]. Then patient presented received iron chelating treatment with Desferal 3 times in 8 -9-day cycles, including the period before and after bone marrow transplantation.

In Poland, deferasirox - a more effective iron-chelating drug taken orally, is not refunded for adults. In patients scheduled for allo-HSCT, most guidelines recommend maintaining the serum ferritin level below 1000ug/l by early chelation. In the presented case, recommended serum ferritin level was not obtained, which may have resulted in an unsatisfactory response to the treatment of both diseases. This rare coexistence of specific skin lesions and high risk MDS clearly underlines the influence of comorbidities on long-term survival.

\section{CONCLUSIONS}

1. MDS is characterized by an increased risk of serious infections, mainly bacterial.

2. Multiple axillary abscesses with bacterial etiology are rarely observed in patients with MDS.

3. Not using azacitidine immediately after bone marrow transplantation and a high serum ferritin level, as well as the coexistence of MDS and bacterial skin lesions, could have contributed to the unsatisfactory response to the treatment of both diseases.

\section{REFERENCES}

1. Dwilewicz-Trojaczek J. Zespoły mielodysplastyczne (MDS). In: Interna Szczeklika. Mały podręcznik. 2017/2018 pod redakcją Piotra Gajewskiego. Kraków: Medycyna Praktyczna; 2017. 951-954.

2. Leone G, Pagano L. Infections in Myelodysplastic Syndrome in relation to Stage and Therapy. Mediterr J Hematol Infect Dis. 2018; 10(1): e2018039.

3. Dayyani F, Conley AP, Strom SS, et al. Cause of death in patients with lower - risk myelodysplastic syndrome. Cancer. 2010; 116(9): 2174-9.

4. Greenberg PL, Stone RM, Al-Kali A, et al. Myelodysplastic Syndromes, Version 2. 2017, NCCN Clinical Practice Guidelines in Oncology. J Natl Compr Canc. 2017; 15(1): 60-67.

5. Toma A, Fenaux P, Dreyfus F, Cordonnier C. Infections in Myelodysplastic Syndromes. Haematologica. 2012; 97: 1459-1470.

6. Acquaviva C, Gelsi-Boyer V, Birnbaum D. Myelodysplastic syndromes: lost between two states? Leukemia. 2010; 24(1): 1-5.

7. Magalhäes RF, Rivitti-Machedo MC, Duarte GV, et al. Consensus on the treatment of hidradenitis suppurativa-Brazilian Society of Dermatology. An Bras Dermatol. 2019 Mar-Apr; 94(2 Suppl 1): 7-19. doi: 10.1590/abd1806-4841.20198607 
8. Salomon J, Piotrowska A, Matusiak , et al. Chitinase - 3-like Protein 1 (YKL-40) is expressed in lesional skin in hidradenitis suppurativa. In Vivo. 2019 Jab-Feb; 33(1): 141-143.

9. Melnik BC, John SM, Chen W, Plewing G. T-helper 17 cell/regulatory T-cell imbalance in hidradenitis suppurativa (acne inversa): the link to hair follicle dissection, obesity, smoking and autoimmune comorbidities. Br J Dermatol. 2018; 179: 260-272.

10. Kantarjian H, Issa JPJ, Rosenfeld CS, et al. Decitabine improves patient outcomes in myelodysplastic syndromes. Cancer. 2006; 106(8): 1794 1780.

11. Fenaux P, Mufti JG, Hellstrom-Lindberg E, et al. Efficacy of azacitidine compared with that of conventional care regimens in the treatment of higher - risk myelodysplastic syndromes: a randomised, open-label, phase III study. Lancet Oncol. 2009; 10(3): 223-232.

12. Merkel D, Filanovsky K, Aviv A, et al. Predictive parameters for infections during azacytidine therapy in high risk MDS patients American Society for Hematology Annual meeting 2011. San Diego. 2011.

13. Trubiano JA, Dickinson M, Thursky KA, et al. Incidence, etiology and timing of infections following azacitidine therapy for myelodysplastic syndromes. Leuk Lymphoma. 2017; 58(10): 2379-2386.
14. Drozd-Sokołowska J, Gil L, Waszczuk-Gajda A, et al. Azacitidine use after allogenic stem cell transplantation - results from the Polish Adult Leukemia Group. Transplant Proc. 2016; 48(5): 1802-1805.

15. Fenaux P, Platzbecker U, Ades L. How we manage adults with myelodysplastic syndrome. Brit J Haematol. 2020; 189: 1016-1027.

16. Zając M, Giannopoulos K. Znaczenie ekspresji nukleofosminy i jej mutacji w ostrej białaczce szpikowej. Acta Haematol Pol. 2011; 42(1): 63-73.

17. Bains A, Luthra R, Medeiros Lj, Zuo Z. FLT3 and NPM1 mutations in myelodysplastic syndromes: Frequency and potential value for predicting progression to acute myeloid leukemia. Am J Clin Pathol. 2011; 135(1): 62-69.

18. Bullen JJ, Rogers HJ, Spalding PB, Ward CG. Natural resistance, iron and infection: a challenge for clinical medicine. J Med Microbiol. 2006; 55(3): 251-258.

19. Wong CAC, Wong SAY, Leitcg HA. Iron overload in lower international prognostic scoring system risk patients with myelodsyplastic syndrome receiving red blood cell transfusions: Relation to infections and possible benefit of iron chelation therapy. Leuk Res. 2018; Feb 10: 67: 75-81.doi: 10.1016/j.leukres.2018.02.005 